\title{
Toward a Designed, Functioning Genetic System With Expanded- size Base Pairs: Solution Structure of the 8-Base xDNA Double Helix
}

\author{
Stephen R. Lynch, Haibo Liu, Jianmin Gao, and Eric T. Kool ${ }^{*}$ \\ Department of Chemistry, Stanford University, Stanford CA 94305-5080
}

\begin{abstract}
We describe the NMR-derived solution structure of the double helical form of a designed 8-base genetic pairing system, termed xDNA. The benzo-homologous xDNA design contains base pairs that are wider than natural DNA pairs by ca. $2.4 \AA$ (the width of a benzene ring). The eight component bases of this xDNA helix are A, C, G, T, xA, xT, xC, and xG. The structure was solved in aqueous buffer using 1D and 2D NMR methods combined with restrained molecular dynamics. The data show that the decamer duplex is right-handed and antiparallel, and hydrogen-bonded in the analogous way as Watson-Crick DNA. The sugar-phosphate backbone adopts a regular conformation similar to that of B-form DNA, with small dihedral adjustments due to the larger circumference of the helix. The grooves are much wider and more shallow than those of B-form DNA, and the helix turn is slower, with ca. 12 base pairs per $360^{\circ}$ turn. There is extensive intra- and inter-strand base stacking surface area, providing an explanation for the greater stability of xDNA relative to natural DNA. There is also evidence for greater motion in this structure compared to a previous two-base expanded helix; possible chemical and structural reasons for this are discussed. The results confirm paired selfassembly of the designed xDNA system. This suggests the possibility that other genetic system structures besides the natural one might be functional in encoding information and transferring it to new complementary strands.
\end{abstract}

\section{Keywords}

genetic system; NMR structure; base pair; benzopyrimidine; benzopurine; stacking; hydrogen bonding

\section{Introduction}

We have recently undertaken a program to design and develop a new functioning genetic system using expanded-size base pairing. The steps to this end are to design new nucleobases and new nucleoside building blocks, to assemble a new DNA-like molecule that can encode sequence information, and ultimately, to develop enzymes that can replicate this genetic set, establishing storage and transfer of genetic information. This strategic program serves two purposes. First, by recapitulating the properties and activities of the natural genetic system, we hope to gain new insights into how biological information is stored and transferred in the natural system. Second, we expect that the both the nucleotides and oligomers of xDNA, which are

*to whom correspondence should be addressed: kool@stanford.edu.

Supporting Material Available

Additional 2D spectral data and chemical shift tables (27 pages). 
inherently fluorescent, may serve as useful biophysical and biomedical tools for probing living systems.

A number of laboratories have been designing new bases and base pairs to function in the context of the natural genetic system. ${ }^{1 \mathrm{a}-\mathrm{q}}$ The present approach is different from that previous work because the expanded pairing set has not just one, but all base pairs replaced, and although structurally related, these pairs have a geometry different from that of Watson and Crick. Because of the large variations in base size, eight-base xDNA strands are not able to bind natural DNA, and are thus structurally orthogonal to the natural genetic system. In addition to studying modified nucleobases, a few laboratories have also investigated the replication of modified nucleic acid backbones. ${ }^{2 a-d}$ Our own research has focused instead on the bases because they (as opposed to the deoxyribose-phosphodiester backbone) are the site of information storage by defining sequence.

Our molecular design for expansion of pairs involves benzo-homologation of DNA bases, ${ }^{3}$ a strategy first reported by Leonard in a lin-benzoadenine ribonucleotide in 1977.4 When extended to new designs for both pyrimidines and purines, this produces size-expanded bases and base pairs. ${ }^{5}$ Two geometries for size expansion have been explored: $x^{2} \mathrm{~A}^{5 \mathrm{a}}, 6$ and yDNA, 7 which have related benzo-homologation but with different vector orientations of expansion. The present study focuses on the former design. xDNA helices are more thermally stable than DNA, and have a similar sequence selectivity against mismatches. ${ }^{8}$ xDNA bases (Figure 1) are fluorescent, and oligomeric strands composed of the four expanded bases can recognize natural DNA and RNA, suggesting possible applications in sensing and imaging of biological sequences.

A recent report described the completion of the synthesis of the four expanded xDNA components and their assembly into 8 -component double-stranded complexes. ${ }^{8}$ To function like a biologically active genetic system, such polymers presumably must self-assemble into pairs of bases having a regular structure (Fig. 1). An early structural study of a 2-base expanded DNA helix ${ }^{9}$ revealed an antiparallel paired geometry. However, an eight-base system is much more complex, and raises several important questions. For example, are all the pairs in the full xDNA pairing system isoplanar and hydrogen bonded, analogous to DNA? Are all base pairs, involving expanded pyrimidines as well as expanded purines, structurally isomorphous? Is the helix antiparallel and right-handed, as with most sequences of natural DNA? What is the rise and twist of the helix, and how does this affect the dimensions of the grooves? How is the structure of the full, complex-sequence 8-base xDNA helix different from the preliminary 2base system, and from DNA itself? The present study addresses these questions. We find that the 8-base xDNA genetic strands do assemble into a paired helix with remarkable similarities to natural DNA, and yet with distinct structural features that arise from the large sizes of the novel base pairs. The results also provide insight into the high stability of the expanded helical system.

\section{Results}

\section{Sequence design and properties}

For structural studies we chose a sequence putatively containing only expanded pairs, i.e., each pair containing one benzo-homologous base and one natural complementary base. Our goal was to evaluate structure in a case of greatest complexity, where all four expanded bases were present (as opposed to an early structure, which contained only the xA base). Ideally, the expanded bases would be scattered on both strands, and a wide variation of nearest neighbor arrangements would be present, to allow for several different stacking arrangements. Because of the large number of nucleotide components (eight), xDNA has sixty-four possible nearest neighbor arrangements, in contrast to DNA where there are sixteen. 
We chose the decamer sequence shown in Fig. 1B to meet these requirements. The sequence contains all eight components of xDNA scattered on both strands, and all nine nearest neighbors are unique. The pair of oligomers having this sequence was recently shown to form a 1:1 complex with a cooperative melting transition at $63{ }^{\circ} \mathrm{C},{ }^{8}$ but no other structural information about helicity and pairing was known. We prepared these two oligomers on larger scales for NMR studies, and purified them by reverse-phase HPLC.

\section{Acidity of $\mathrm{dxG}$}

Preliminary 1-D NMR studies in water (see below) suggested that the imino proton of $d x G$ was in more rapid exchange with solvent than is commonly seen for dG (Fig. 2). We therefore explored the effect of benzo-homologation on the acidity of this nucleobase by measuring the acidic $\mathrm{pKa}$ of the free nucleoside in water. This was done following a published protocol, 10 evaluating perturbations in $\mathrm{pH}$ with small equivalents of base added. The data yielded a $\mathrm{pKa}$ value of $7.3 \pm 0.3$ for $d x G$. This base-induced ionization, presumably of the imino $\mathrm{N}-\mathrm{H}$ proton, is nearly two full $\mathrm{pK}$ units more acidic than the reported $\mathrm{pKa}$ of 9.2 for the imino proton of native dG. ${ }^{11}$

\section{NMR experiments}

The two component strands of the sequence in Fig. 1B were mixed to 1:1 molar ratio by following imino protons, and subsequently, ${ }^{1} \mathrm{H} 1 \mathrm{D},{ }^{1} \mathrm{H} /{ }^{1} \mathrm{H},{ }^{1} \mathrm{H} /{ }^{13} \mathrm{C}$, and ${ }^{1} \mathrm{H} /{ }^{31} \mathrm{P} 2 \mathrm{D}$ NMR spectra were acquired on the duplex in a buffer containing $20 \mathrm{mM}$ sodium phosphate. A portion of the $2 \mathrm{D}{ }^{1} \mathrm{H} /{ }^{13} \mathrm{C}$ HSQC is shown in Figure S1A. The dispersion of the resonances was good, indicating an ordered three-dimensional structure. All non-exchangeable proton resonances were assigned to specific protons in the DNA molecule, except for a few of the H5'/H5" protons, with a combination of 2D NMR techniques including ${ }^{1} \mathrm{H} /{ }^{1} \mathrm{H}$ DQF-COSY, TOCSY, and NOESY, ${ }^{1} \mathrm{H} /{ }^{13} \mathrm{C}$ HSQC and HMBC, and ${ }^{1} \mathrm{H} /{ }^{1} \mathrm{P}$ heteronuclear-COSY. The assigned proton and ${ }^{13} \mathrm{C}$ resonances are tabulated in the Supporting Information file.

The $1 \mathrm{D}{ }^{1} \mathrm{H}$ NMR spectrum acquired in $\mathrm{H}_{2} \mathrm{O}$ at $\mathrm{pH}$ 7.0, showing the downfield-shifted imino protons of guanine, thymine and extended variants, is shown in Figure 2. Five imino resonances were observed to be sharp, and were assigned in combination with ${ }^{1} \mathrm{H} /{ }^{1} \mathrm{H}$ NOESY acquired in $\mathrm{H}_{2} \mathrm{O}$. A sixth sharp resonance in the downfield region of the NMR spectrum was assigned to a second $\mathrm{NH}$ resonance present on the x-pyrimidines; the other four such resonances of the $\mathrm{x}$ pyrimidines were observed further upfield, and are not shown.

Each Watson-Crick-like base pair of xDNA is expected to have an imino proton hydrogenbonded to the complementary base (Fig. 1A); thus, one would expect to observe as many as ten imino proton resonances. However, only five imino proton resonances were observed as sharp and assignable; the other five expected resonances were not assigned. The imino proton resonances for the two terminal base pairs were not observed, presumably due to rapid exchange with water; this result is normal for NMR spectra of DNA duplexes. The other three imino proton resonances that were not observed correspond those of the $\mathrm{xG}$ bases. Broad resonances potentially belonging to the imino protons of $\mathrm{xG}$ were observed between 10.5 and $12.5 \mathrm{ppm}$ (Figure 2).

Studies of free $\mathrm{dxG}$ in solution (above) showed a significantly lower pKa than that of G. Assuming that the NH protons of $\mathrm{xGs}$ in the duplex were to have a lower $\mathrm{pKa}$ as well, then one would expect broadening of the $\mathrm{NH}$ resonance due to exchange. In preliminary experiments, lowering the $\mathrm{pH}$ of the buffer below 7.0 caused some sharpening of the broad resonances; however, the other resonances broadened and no additional assignments could be made. 
To explore this absence of resonances further, 1D NMR and 2D NMR data were acquired in $\mathrm{D}_{2} \mathrm{O}$ buffer at varied $\mathrm{pH}$ values (Figure $2 \mathrm{~B}$ ). The data showed that although many of the protons were unaffected by $\mathrm{pH}$ (in portions of the aromatic region not shown), resonances of $\mathrm{xG}$ and adjacent bases were clearly affected by $\mathrm{pH}$ in the 6.8-7.8 range. The change in chemical shift and broadening of the set of resonances were consistent with local conformational or structural change correlated to $\mathrm{pH}$. As all of the observed changes were either on the proton resonances of the $\mathrm{xG}$ nucleotides or protons on nucleotides close in space to an $\mathrm{xG}$ residue, this is consistent with protonation/de-protonation leading to the observed $\mathrm{pH}$ induced broadening and change in chemical shift. This event would likely be from the N1 position of $\mathrm{xG}$, on the Watson-Crick face. The actual $\mathrm{pKa}$ values of the three $\mathrm{xG}$ residues were not measurable with NMR, as $\mathrm{pH}$ values of 8.0 and above caused general broadening of the NMR spectrum (data not shown), making interpretation difficult. At the pKa, the linewidth of the resonance should be the broadest, which implies that the $\mathrm{pKa}$ is 7.8 or higher for the imino proton for all three $\mathrm{xG}$ bases in the duplex.

Although the imino proton resonances were not observable for the $\mathrm{xG}$ bases, the helix is intact as confirmed by NOESY spectra acquired in $\mathrm{D}_{2} \mathrm{O}$ buffer (Figure 3 and Figure $\mathrm{S} 2$ in the Supporting file). NOEs were observed between the two strands of xDNA from xA8 on one strand and $\mathrm{xG} 14$ on the other strand. The $\mathrm{H} 2$ proton on $\mathrm{xA}$ is on the Watson-Crick-analogous face of the nucleotide and thus is normally close to the other strand in a Watson-Crick-like base-pair. In addition to the cross-strand NOEs between xA8 and xG14, the expected NOEs indicating base stacking from successive nucleotides were also observed, including those between $\mathrm{xC} 5$ and $\mathrm{xG} 6, \mathrm{xA} 8$ and $\mathrm{xG} 9, \mathrm{xG} 9$ and $\mathrm{T} 10, \mathrm{~T} 13$ and $\mathrm{xG} 14$, and $\mathrm{xG} 14$ and $\mathrm{C} 15$. Thus the data confirm that although the $x G$ hydrogen-bonded resonances are not observable, the three $\mathrm{xG}$ residues and their partners are located in the helix and are stacked as expected with the neighboring bases.

\section{Structure of the duplex containing eight different bases}

Structures of the decamer duplex were calculated from 635 NOEs, 80 experimentally determined dihedral constraints, and 25 hydrogen bonds for the Watson-Crick-like base pairs. The structure statistics for the set of 20 converged structures is presented in Table 1. The superposition of these structures is presented in Figure 4. The overall heavy-atom r.m.s.d. for the 10 nucleotide duplex is $1.18 \AA$. The primary reasons for disorder in the duplex is slight changes of helical bending, which is difficult to define by NMR due to the lack of long range constraints; disorder at the terminal base pairs, which is common as there are fewer internucleotide NOEs to terminal nuclei; and the disorder correlated to the $\mathrm{xG}$ base. The resonances for the $\mathrm{xG}$ nucleotide as well as those of protons close in space to the $\mathrm{xG}$ imino proton were broad as shown in Figure 2B. Fewer NOEs to these resonances were observed due to the putative exchange event, leading to fewer distance constraints near these residues.

The average structure of the xDNA duplex is shown in Figure 4B. The structure is a righthanded helix that is globally similar to B-DNA with the twenty bases in the anti conformation and the sugars in $\mathrm{C} 2$ '-endo conformation. Table 2 compares structural parameters of this xDNA structure and generic B-DNA. The most obvious difference is the width of the helix, and the width and depth of the two grooves, particularly the minor groove. This marked difference in groove dimensions is obvious in surface models (Figure 5). In addition, there is a significant difference in residues per turn ( 12 for xDNA versus 10 for B-DNA), which is correlated to the difference in helix twist $\left(36^{\circ}\right.$ versus $\left.30^{\circ}\right)$.

The structures of the four different base pair combinations from the average structure are shown in Figure 6. The Watson-Crick-analogous geometries are observed for each of the pairs. The most notable feature is the extensive stacking overlap of $\mathrm{xA}$ and $\mathrm{xG}$ with each other. The $\mathrm{x}-$ purines within the same strand have extensive amounts of shared surface contact (see Fig. 6B), 
such as in the case of $x A 8$ and $x G 9$. Even when situated in opposite strands, $x$-purines overlap to a significant degree when in adjacent pairs; examples are found with $\mathrm{xA} 8$ and $\mathrm{xG14}$, and $\mathrm{xG} 14$ and $\mathrm{xG} 6$.

\section{Discussion}

We previously reported the structure of a simple expanded DNA helix consisting of only two bases (xA and T). ${ }^{9}$ Notable features of that structure included a well-defined xA-T hydrogen bonded pair, and a widened groove structure. However, the simple nature of the sequence of that structure left open the possibility that more complex sequences containing xDNA building blocks might form different structures. Indeed, in natural DNA it is known that while most sequences of DNA usually assemble into the B-type canonical helix, a number of simple sequences form very different structures. Examples include the parallel-stranded structures formed by A,T-DNA, ${ }^{12}$ triple helices formed in purine stretches, ${ }^{13}$ curved structures found with runs of adenines, ${ }^{14}$ and quadruplexes formed in G-rich DNA. ${ }^{15}$ Interestingly, early evidence suggests that certain homo-x-pyrimidine sequences of xDNA may in fact form triple helices with homopurine DNAs. $6 \mathrm{~b}$

The current study addresses the structure of the complete eight-base xDNA genetic set for the first time. The full sequence complexity of xDNA is approached in the current sequence by presenting four different base pairs (composed of eight different bases) in nine nearest neighbor contexts. Overall, the results confirm that the four xDNA pairs are, on average, hydrogen bonded in the expected way, and that the xDNA helix is right-handed with pairs oriented roughly perpendicular to the helix, analogous to the previous simpler xDNA structure. ${ }^{9}$ Compared with that earlier structure, the helix twist per pair and the helix diameter are almost the same (Table 2). However, there are some notable differences as well. There is a greater rise per base pair ( $4.0 \AA$ vs 3.1 earlier) and greater helix pitch ( $46 \AA$ vs 37$)$. The base pair inclination ( $24^{\circ}$ in the current structure vs. $-0.5^{\circ}$ before) is considerably greater. Finally, the grooves are shallower in the more complex sequence structure (2.5-2.6 $\mathrm{A}$ vs. 7-8 $\AA$ previously). This latter difference, and perhaps some of the other deviations as well, likely arise from the presence of $\mathrm{xC}-\mathrm{G}$ and $\mathrm{xT}$-A pairs, which are geometrically somewhat different from the $\mathrm{xA}$ $\mathrm{T}$ pair that made up the earlier simple sequence (see Figs. 1 and 7). The $\mathrm{x}$-pyrimidines possess major groove methyl groups that make that groove shallower on average, and the x-pyrimidine geometry causes them to project further into the minor groove than do x-purines, effectively raising the floor of that groove as well.

Another substantial difference between the present 8-base xDNA structure and that of the earlier simple 2-base system is the current observation of greater dynamics in the base pairs. We suggest two explanations for this. First is the ionization equilibrium and solvent exchange of the $\mathrm{xG}$ imino protons. To the extent that this base is ionized in the helix, this might promote pair opening and interaction with solvent. Our observation of broad or missing $\mathrm{NH}$ protons of $\mathrm{xG}$ residues and $\mathrm{pH}$-dependent line broadening near these bases is consistent with such motions. A second possible explanation is the small but significant difference in geometry of pairs involving $\mathrm{x}$-purines as compared with x-pyrimidines (Fig. 7). This difference is likely to require small backbone and pair geometry adjustments when such pairs are adjacent, and so some small degree of conformational shifts resulting from this would not be surprising. Either or both of these factors may contribute to the observed heavy-atom r.m.s.d. of $1.18 \AA$ (Table 1 ), which is somewhat higher than that of the earlier (and simpler) 2-base structure (0.84 $\AA$ ).

Overall, the current results confirm that mixed-sequence xDNA can pair and assemble sequence-specifically into a regular double helix in a predictable way. This specific selfassembly is an important feature of functioning genetic systems, which must store and transfer genetic information as a sequence of bases. DNA strands must be able to spontaneously form 
stable complexes after being denatured globally (such as in PCR) or locally (as during transcription). Moreover, the functioning of the natural genetic system in information transfer (such as during replication) requires a regular geometry of base pairs so that enzymatic copying can occur in a sequence-generic way. The present work shows that the eight-base xDNA system may have most if not all of these features, which suggests the future possibility of a functioning, replicable genetic system using xDNA as the genetic material. Of course it remains to be seen whether XDNA can in fact be replicated; this is expected to be a significant challenge since replicative DNA polymerases can be highly sensitive to the size of base pairs. ${ }^{16}$

On the practical level, this study shows that xDNA pairs can assemble in the predicted way, using complementarity of size, shape and hydrogen bonding to assemble an antiparallel, regular helix. We have previously shown that strands composed entirely of the four expanded DNA bases can recognize natural DNA and RNA, ${ }^{8}$ and the current results indicate that such recognition is structurally predictable in the same way as natural DNA assembly. Because xDNA bases are inherently fluorescent and form highly stable helices, this could lead to future development of useful tools for probing and detection of nucleic acids.

\section{Experimental Section}

\section{Oligonucleotide synthesis and purification}

The deoxynucleoside phosphoramidite derivatives of the four benzo-homologated nucleosides were prepared as described previously. ${ }^{17}$ The two $10 \mathrm{mer}$ strands of the present duplex were prepared as reported. ${ }^{8}$ Briefly, sequences contained a 3' phosphate group using a ' 3 'phosphate-ON" controlled pore glass support (Glen Research). Oligonucleotides were synthesized using an Applied Biosystems 392 synthesizer in trityl-off mode using standard $\beta$ cyanoethylphosphoramidite chemistry. Two 1-umole syntheses of each sequence were performed and the products combined for each. Oligonucleotides were deprotected and removed from solid support with concentrated ammonia. They were purified by reverse-phase HPLC and quantitated by UV absorption.

\section{NMR structural studies}

NMR experiments were acquired on either a Varian Inova $600 \mathrm{MHz}$ NMR instrument or Varian Inova $500 \mathrm{MHz}$ NMR instrument equipped triple resonance and z-gradient or triple axis gradient capabilities. NMR spectra were acquired at $25^{\circ} \mathrm{C}$ in $20 \mathrm{mM}$ sodium phosphate, $\mathrm{pH}$ 7.0, exchanged into $99.996 \% \mathrm{D}_{2} \mathrm{O}$, or at $2{ }^{\circ} \mathrm{C}, 15^{\circ} \mathrm{C}$, and $25^{\circ} \mathrm{C}$ in $90 \% \mathrm{H}_{2} \mathrm{O} / 10 \% \mathrm{D}_{2} \mathrm{O}$ in 20 $\mathrm{mM}$ sodium phosphate buffer, $\mathrm{pH}$ 7.0. ${ }^{1} \mathrm{H}$ resonances were assigned with standard methods using a combination of DQF-COSY, TOCSY with mixing times of $20 \mathrm{~ms}$ and $80 \mathrm{~ms},{ }^{1} \mathrm{H} /{ }^{13} \mathrm{C}$ HSQC, ${ }^{1} \mathrm{H} /{ }^{31} \mathrm{P}$ heteronuclear COSY, ${ }^{1} \mathrm{H} /{ }^{13} \mathrm{C}$ HMBC, NOESY, and SS-NOESY experiments. The spectral width in the ${ }^{1} \mathrm{H}$ dimension for all experiments in $\mathrm{D}_{2} \mathrm{O}$ was $10 \mathrm{ppm} .{ }^{1} \mathrm{H} /{ }^{13} \mathrm{C}$ HSQC was acquired with 2048 points in $\mathrm{t} 2$ dimension by 128 real points in $\mathrm{t} 1$ dimension with a recycle delay of 2.5 seconds and a carbon spectral width of $70 \mathrm{ppm}$ for the aromatic resonances, and 2048 by 256 with 1.8 seconds recycle delay and a spectral width of $40 \mathrm{ppm}$. DQF-COSY was acquired with 16 scans of 8192 points in $\mathrm{t} 2$ dimension by 512 points in $\mathrm{t} 1$ dimension with an acquisition time of $0.682 \mathrm{~s}$, and a recycle delay of $0.75 \mathrm{~s}$. TOCSY experiments were acquired with 16 scans of 4096 points in t 2 by 400 points in $t 1$ with an acquisition time of $0.341 \mathrm{~s}$ and a recycle delay of 0.75 seconds. NOESY experiments in D2O were acquired with mixing times of $50 \mathrm{~ms}, 100 \mathrm{~ms}, 150 \mathrm{~ms}$, and $300 \mathrm{~ms}$ with 32 scans of 4096 points in t 2 and 400 in t 1 with an acquisition time of $0.341 \mathrm{~s}$, and a recycle delay of $1.5 \mathrm{~s}$. SS-NOESY experiments were acquired in $90 \% \mathrm{H}_{2} \mathrm{O}$ with mixing times of $75 \mathrm{~ms}$ and $250 \mathrm{~ms}$, with 160 scans of 4096 by 256 points, and acquisition time of $0.179 \mathrm{~s}$, and a recycle delay of 1.5 seconds with a $19 \mathrm{ppm}$ wide spectral width. 
NMR data were processed using Varian VNMR 6.1C software. Display of NMR data, coupling constant measurement, and calculation of NOE volumes were accomplished in the NMR display program out using SPARKY $3 .{ }^{18}$

The protons on the deoxyribose residues were distinguished by type with ${ }^{1} \mathrm{H} /{ }^{13} \mathrm{C}$ HSQC acquired in natural abundance and separated into nucleotide spin systems with TOCSY and assigned with DQF-COSY. The deoxyribose protons were correlated to the base by ${ }^{1} \mathrm{H} /{ }^{13} \mathrm{C}$ $\mathrm{HMBC}$ when possible or with strong intranucleotide NOEs between $\mathrm{H} 2^{\prime}$ and $\mathrm{H} 6$ for thymidine and cytidine, $\mathrm{H} 2^{\prime}$ and $\mathrm{H} 8$ for adenosine and guanosine, and $\mathrm{H}^{\prime}$ and $\mathrm{Hd}$ and the $\mathrm{H} 2^{\prime}$ and $\mathrm{H} 8$ for xA (see SI for numbering). The protons on the aromatic ring of the eight different nucleotides could be distinguished from each other by ${ }^{13} \mathrm{C}$ chemical shift as observed in ${ }^{1} \mathrm{H} /{ }^{13} \mathrm{C} \mathrm{HSQC}$. These proton resonances were assigned by a combination of TOCSY correlation to each other through-bond or NOESY correlation through-space. Sequential assignments were made through many NOEs observed between sequential nucleotides including protons on the deoxyribose to the protons on the sequential base and protons on one base to protons on the sequential base. The imino protons of $\mathrm{T}, \mathrm{xT}, \mathrm{G}$, and $\mathrm{xG}$ could be assigned based upon imino-imino NOEs between sequential base-pairs, and intense NOEs between the $\mathrm{T}$ and $\mathrm{xT}$ imino to the $\mathrm{H} 2$ proton of $\mathrm{xA}$ (see the numbering in the supporting file), or the $\mathrm{H} 2$ proton of A. Additional NOEs were observed between the $\mathrm{H} 2$ of $\mathrm{xA}$ or the $\mathrm{H} 2$ of A to imino protons of sequential base-pairs to confirm assignments.

\section{Structure Calculation}

Structures of the decamer DNA duplex were calculated on an SGI Octane workstation with restrained molecular dynamics followed by energy minimization with the program CNS. ${ }^{19}$ The nonnatural bases were created first by building them with InsightII (Accelrys, San Diego, CA), and outputting coordinate and parameter files of bond lengths, angles, and improper angles into CNS. These bases were combined with the deoxyribose to make a coordinate file of the four nonnatural bases. The normal parameter file for deoxynucleotides in CNS was modified to include the nonnatural bases. The nonnatural nucleotides were then connected to the natural ones in the proper sequence of the two strands in the CNS program.

One hundred random starting structures were created by giving different initial velocities to an elongated single strand of each of the two complementary oligonucleotide sequences. These structures were subjected to a simulated annealing protocol with restrained torsion angle dynamics using a force field of bond lengths, bond angles, improper angles, repulsive van der Waals potentials, and experimental distance and torsion angle constraints. NOE force constants were set at $50 \mathrm{kcal} / \mathrm{mol} \AA^{2}$; torsion angle force constants were varied from 10 to $50 \mathrm{kcal} / \mathrm{mol}$ $\AA^{2}$. The high temperature annealing was done with 4000 cycles molecular dynamics for 60ps at $20000 \mathrm{~K}$ with low values of interatomic repulsion, followed by 1000 steps of torsion angle dynamics while cooling to $2000 \mathrm{~K}$, and slow cooling with 2000 steps of Cartesian dynamics while cooling to $300 \mathrm{~K}$, increasing the dihedral force constant from 10 to $50 \mathrm{kcal} / \mathrm{mol} \AA^{2}$. An initial energy minimization with 200 steps with both the NOE and dihedral force constants at $50 \mathrm{kcal} / \mathrm{mol} \AA^{2}$ was accomplished. Of 100 initial structures, the 20 lowest energy structures were subjected to a second stage of 2500 cycles of molecular dynamics at $300 \mathrm{~K}$; this was followed by a final energy minimization that included all of the above constraints in addition to attractive Lennard-Jones potentials without electrostatic potentials for 3000 steps. The final structures were superimposed and displayed with either the program MOLMOL ${ }^{20}$ or PyMOL. 21

Distance restraints for non-exchangeable protons were assigned based upon analysis of crosspeak intensity in $\mathrm{D}_{2} \mathrm{O}$ NOESY experiments with mixing times of $50 \mathrm{~ms}, 100 \mathrm{~ms}, 150 \mathrm{~ms}$ and $300 \mathrm{~ms}$, and SS-NOESY experiments in $\mathrm{H}_{2} \mathrm{O}$ with 75 and $250 \mathrm{~ms}$ mixing time. NOEs were assigned as strong (1.8-3.0 ̊), medium (2.3-4.5 ̊), and weak (3.0-6.0 ̊). Hydrogen bonds 
for the Watson-Crick like base pairs were assigned based upon intense NOEs observed between the thymine or $\mathrm{x}$-thymidine imino proton and $\mathrm{x}$-adenosine $\mathrm{H} 2$ or adenosine $\mathrm{H} 2$ proton, or the guanosine or imino proton and the $\mathrm{x}$-cytidine amino protons, as well as the downfield chemical shift of the imino proton resonance. The $\mathrm{x}$-guanosine/cytosine base pairs and terminal base pairs were modeled as Watson-Crick-like pairs even though the imino protons could not be observed due to solvent exchange.

Dihedral constraints were assigned based on analysis of DQF-COSY and ${ }^{1} \mathrm{H} /{ }^{31} \mathrm{P}$ heteronuclear

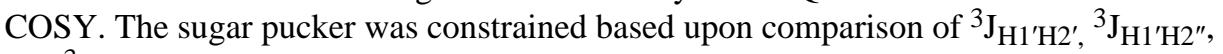
and ${ }^{3} \mathrm{~J}_{\mathrm{H} 3^{\prime} \mathrm{H} 4^{\prime}}$ values. All nucleotides were determined to be $\mathrm{C}^{\prime}$-endo except for the terminal thymidine and $\mathrm{x}$-thymidine which observed to be in conformational exchange. The backbone torsion angle $\beta$ was estimated based upon measurement of ${ }^{3} \mathrm{~J}_{\mathrm{H} 5^{\prime} \mathrm{p}},{ }^{3} \mathrm{~J}_{\mathrm{H} 5}{ }^{\prime \prime} \mathrm{P}$, and ${ }^{4} \mathrm{~J}_{\mathrm{H} 4^{\prime} \mathrm{P}}$, and assigned a range of $\pm 30^{\circ}$. The backbone torsion angle $\gamma$ was estimated based upon measurement of ${ }^{3} \mathrm{~J}_{\mathrm{H} 4^{\prime} \mathrm{H} 5^{\prime},}{ }^{3} \mathrm{~J}_{\mathrm{H} 4^{\prime} \mathrm{H} 5^{\prime \prime}}$, and ${ }^{4} \mathrm{~J}_{\mathrm{H} 4^{\prime} \mathrm{P}}$, and assigned a range of $\pm 30^{\circ}$.

\section{Helical Parameters}

The helical parameters and torsion angles for the decamer duplex were determined using the program CURVES 5.3 by inputting the structures in pdb format into the program after final energy minimization. 22

\section{Supplementary Material}

Refer to Web version on PubMed Central for supplementary material.

\section{Acknowledgement}

This work was supported by the U.S. National Institutes of Health (GM63587).

\section{References}

1. (a) Switzer CY, Moroney SE, Benner SA. Biochemistry 1993;32:10489-10496. [PubMed: 7691174] (b) Rappaport HP. Nucleic Acids Res 1988;16:7253-7267. [PubMed: 3412886] (c) Schweitzer BA, Kool ET. J. Am. Chem. Soc 1995;117:1863-1872. (d) Tae EL, Wu Y, Xia G, Schultz PG, Romesberg FE. J. Am. Chem. Soc 2001;123:7439-7440. [PubMed: 11472182] (e) Mitsui T, Kitamura A, Kimoto M, To T, Sato A, Hirao I, Yokoyama S. J. Am. Chem. Soc 2003;125:5298-5307. [PubMed: 12720441] (f) Matray TJ, Kool ET. J. Am. Chem. Soc 1998;120:6191-6192. (g) Henry AA, Romesberg FE. Curr. Opin. Chem. Biol 2003;7:727-733. [PubMed: 14644182] (h) Lai J, Qu J, Kool ET. J. Am. Chem. Soc 2004;126:3040-3041. [PubMed: 15012120] (i) Johnson SC, Sherrill CB, Marshall DJ, Moser MJ, Prudent JR. Nucleic Acids Res 2004;32:1937-1941. [PubMed: 15051811] (j) Atwell S, Meggers E, Spraggon G, Schultz PG. J. Am. Chem. Soc 2001;123:12364-12367. [PubMed: 11734038] (k) Tanaka K, Yamada Y, Shionoya M. J. Am. Chem. Soc 2002;124:8802-8803. [PubMed: 12137526] (1) Weizman H, Tor Y. J. Am. Chem. Soc 2001;123:3375-3376. [PubMed: 11457077] (m) Zhang L, Meggers E. J. Am. Chem. Soc 2005;127:74-75. [PubMed: 15631455] (n) Sismour AM, Benner SA. Nucleic Acids Res 2005;33:5640-5646. [PubMed: 16192575] (o) Minakawa N, Kojima N, Hikishima S, Sasaki T, Kiyosue A, Atsumi N, Ueno Y, Matsuda A. J. Am. Chem. Soc 2003;125:9970-9982. [PubMed: 12914460] (p) Switzer C, Sinha S, Kim PH, Heuberger BD. Angew. Chem. Int. Ed. Engl 2005;44:1529-1532. [PubMed: 15678435] (q) Adelfinskaya O, Nashine VC, Bergstrom DE, Davisson VJ. J. Am. Chem. Soc 2005;127:16000-16001. [PubMed: 16287267]

2. (a) Jung KH, Marx A. Cell Mol. Life Sci 2005;62:2080-2091. [PubMed: 16041567] (b) Chaput JC, Szostak JW. J. Am. Chem. Soc 2003;125:9274-9275. [PubMed: 12889939] (c) Eschenmoser A. Orig. Life Evol. Biosph 2004;34:277-306. [PubMed: 15068036]

3. (a) Godde F, Toulme JJ, Moreau S. Biochemistry 1998;37:13765-13775. [PubMed: 9753465] (b)

Okamoto A, Tanaka K, Saito I. J. Am. Chem. Soc 2003;125:4972-4973. [PubMed: 12708835]

4. Scopes DI, Barrio JR, Leonard N. J. Science 1977;195:296-298. 
5. (a) Liu H, Gao J, Lynch S, Maynard L, Saito D, Kool ET. Science 2003;302:868-871. [PubMed: 14593180] (b) Hikishima S, Minakawa N, Kuramoto K, Fujisawa Y, Ogawa M, Matsuda A. Angew. Chem. Int. Ed 2005;44:596-598.

6. (a) Gao J, Liu H, Kool ET. J. Am. Chem. Soc 2004;126:11826-11831. [PubMed: 15382917] (b) Liu H, Gao J, Kool ET. J. Am. Chem. Soc 2005;127:1396-1402. [PubMed: 15686371]

7. (a) Lu H, He K, Kool ET. Angew. Chem. Int. Ed 2004;43:5834-5836. (b) Lee AHF, Kool ET. J. Am. Chem. Soc 2005;127:3332-3338. [PubMed: 15755149]

8. Gao J, Liu H, Kool ET. Angew. Chem. Int. Ed 2005;44:3118-3122.

9. Liu H, Lynch SR, Kool ET. J. Am. Chem. Soc 2004;126:6900-6905. [PubMed: 15174859]

10. Patterson GS. J. Chem. Ed 1999;76:395-398.

11. Chiang Y, Kresge A. J. Org. Biomol. Chem 2004;2:1090-1092.

12. Rippe K, Jovin TM. Meth. Enzymol 1992;211:199-220. [PubMed: 1383673]

13. (a) Morgan AR, Wells RD. J. Mol. Biol 1968;37:63-80. [PubMed: 5760495] (b) Moser HE, Dervan PB. Science 1987;238:645-650. [PubMed: 3118463]

14. Koo H-S, Wu H-M, Crothers DM. Nature 1986;320:501-506. [PubMed: 3960133]

15. Wiliamson JR, Raghuraman MK, Cech TR. Cell 1989;59:871-880. [PubMed: 2590943]

16. Kim TW, Delaney JC, Essigmann JM, Kool ET. Proc. Natl. Acad. Sci. USA 2005;102:15803-15808. [PubMed: 16249340]

17. (a) Liu H, Gao J, Saito D, Maynard L, Kool ET. J. Am. Chem. Soc 2004;126:1102-1109. [PubMed: 14746479] (b) Liu H, Gao J, Kool ET. J. Org. Chem 2004;70:639-647. [PubMed: 15651812]

18. Goddard TD, Huang CC, Ferrin TE. Structure 2005;13:473-482. [PubMed: 15766548]

19. Brunger AT, Adams PD, Clore GM, Delano WL, Gros P, Grosse-Kunstleve RW, Jiang JS, Kuszewski J, Nilges M, Pannu NS, Read RJ, Rice LM, Simonson T, Warren GL. Acta Crystallogr. D Biol. Crystallogr 1998;54:905-921. [PubMed: 9757107]

20. Koradi R, Billeter M, Wüthrich K. J Mol. Graphics 1996;14:51-55.

21. DeLano, WL. The PyMOL Molecular Graphics System. DeLano Scientific, San Carlos; CA, USA: 2002. http://pymol.sourceforge.net

22. Lavery R, Sklená H. J. Biomol. Struct. Dyn 1988;6:63-91. [PubMed: 2482765] 
A
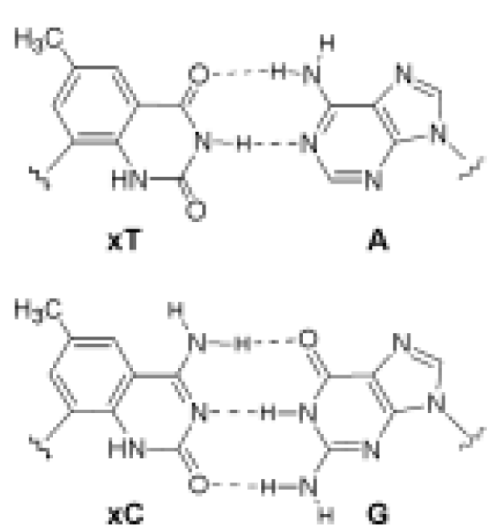
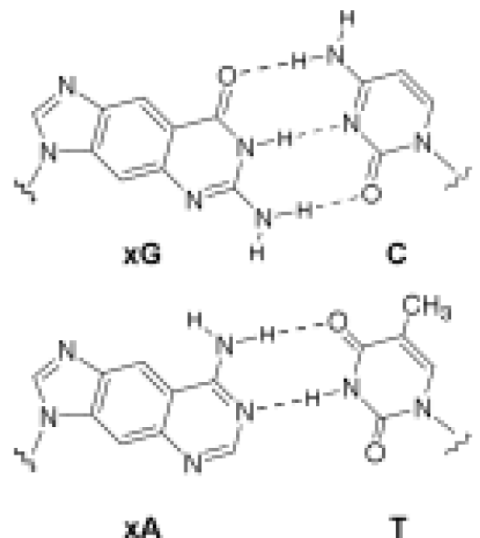

B

$$
\begin{aligned}
& \begin{array}{llllllllll}
1 & 2 & 3 & 4 & 5 & 6 & 7 & 8 & 9 & 10
\end{array} \\
& s=x T-G-x T-A-x C-x G-C-x A-x G-T-x \\
& \text { s- } \mathrm{A}-\mathrm{x} \mathrm{C}-\mathrm{A}-\mathrm{x} \mathrm{T}-\mathrm{G}-\mathrm{C}-\mathrm{xG}-\mathrm{T}-\mathrm{C}-\mathrm{xA}-\mathrm{s} \\
& \begin{array}{llllllllll}
20 & 19 & 18 & 17 & 16 & 15 & 14 & 13 & 12 & 11
\end{array}
\end{aligned}
$$

Figure 1.

Structures and sequences in this study. (A) Proposed xDNA base pairs; (B) strand sequences and residue numbering. 
A

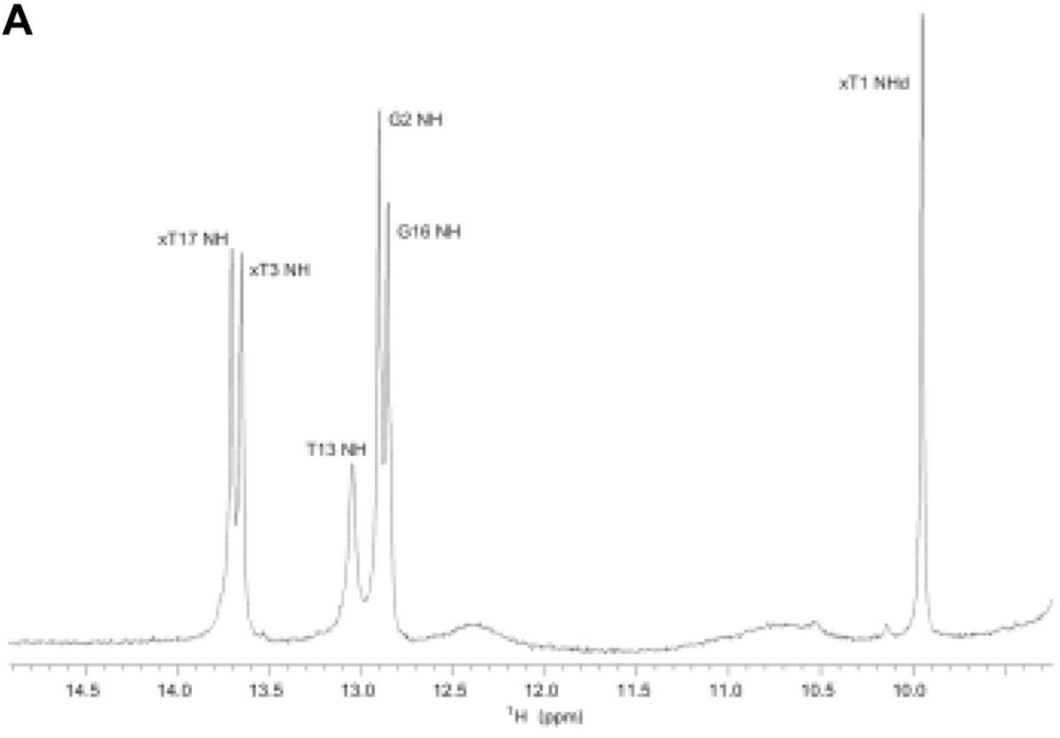

B

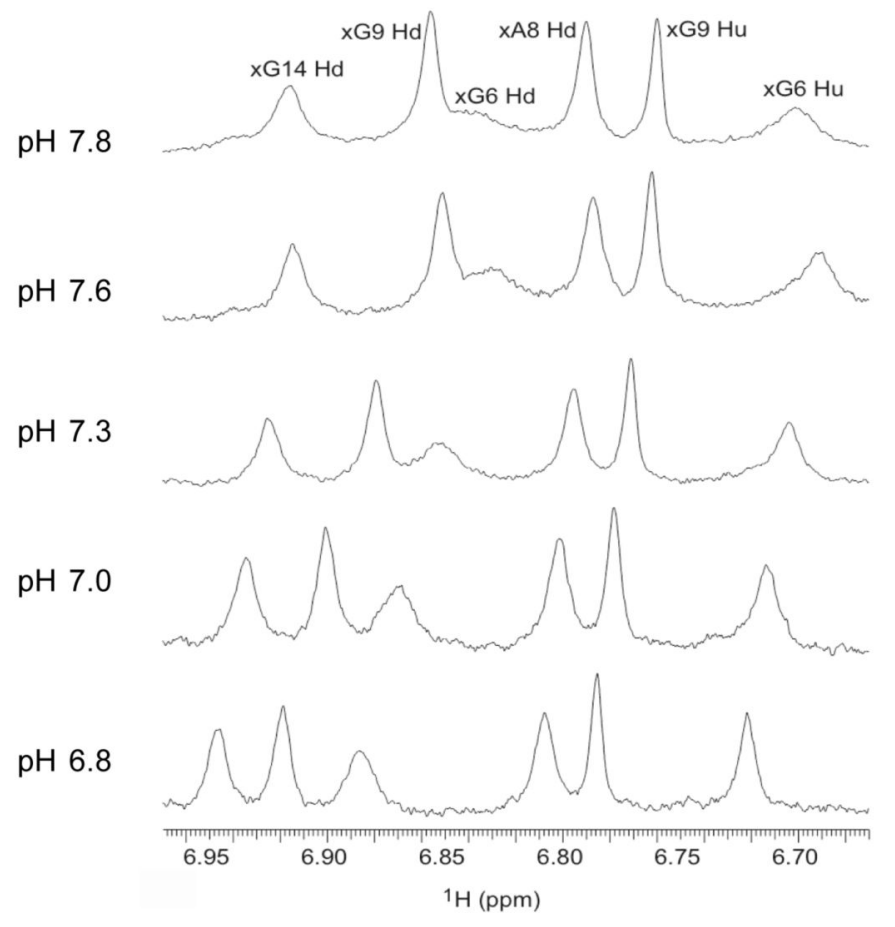

Figure 2.

${ }^{1} \mathrm{H}$ 1D spectra of the $10 \mathrm{mer} x \mathrm{xNA}$ duplex in water. (A) Spectrum acquired in $20 \mathrm{mM}$ sodium phosphate buffer in $\mathrm{H}_{2} \mathrm{O}, \mathrm{pH} 7.0$, showing the downfield shifted imino proton resonances of $\mathrm{G}, \mathrm{T}$, and $\mathrm{xT}$, with $\mathrm{xG}$ resonances missing due to exchange; (B) Spectrum acquired in $20 \mathrm{mM}$ sodium phosphate buffer in $\mathrm{D}_{2} \mathrm{O}$ at various $\mathrm{pH}$ values, showing the $\mathrm{pH}$ dependence of the aromatic proton resonances of $\mathrm{xG}$, and those of protons close in space to $\mathrm{xG}$. 


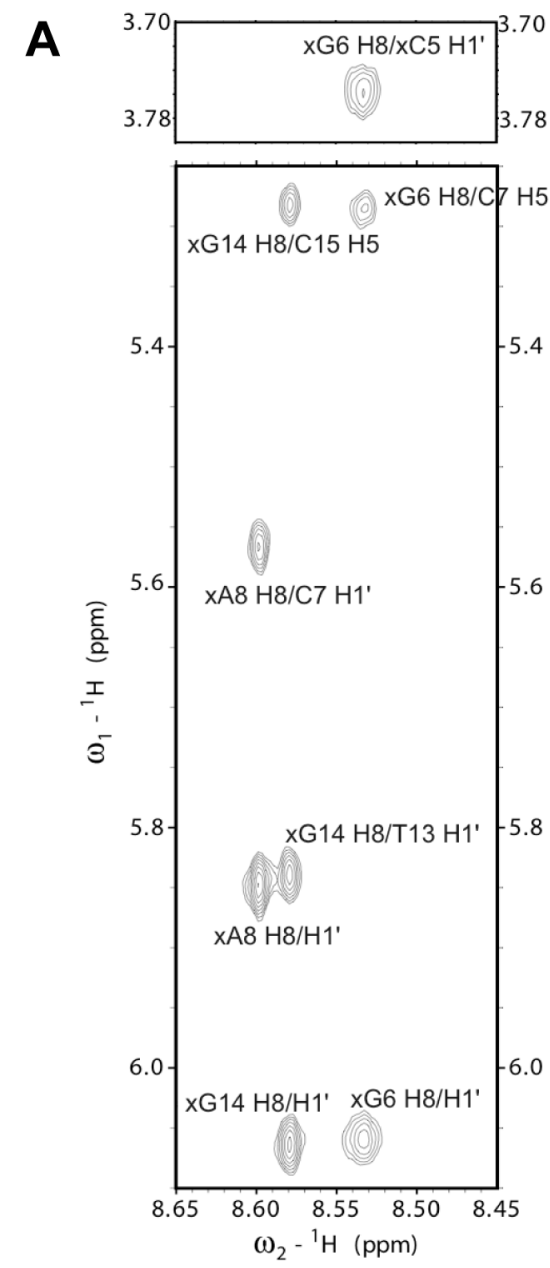

B

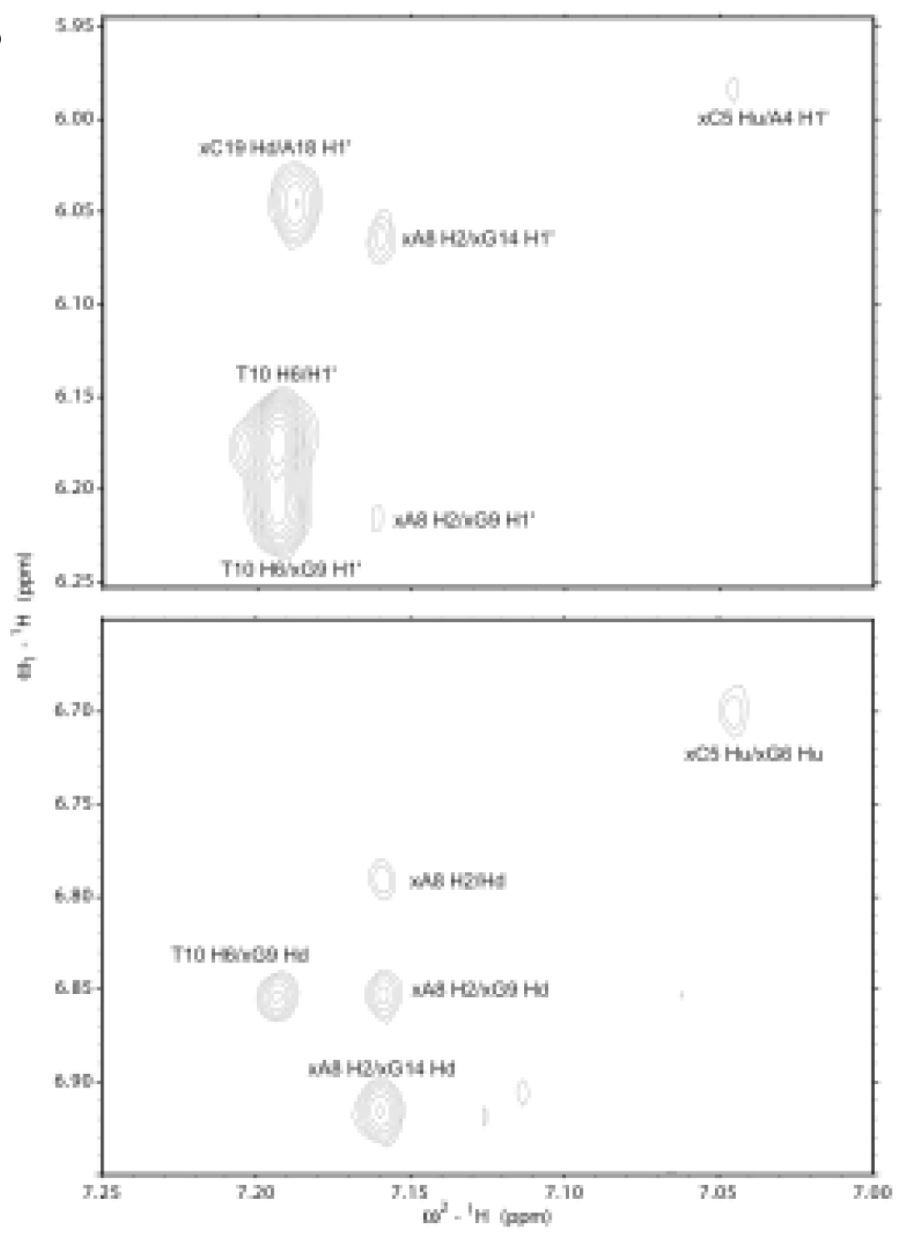

Figure 3.

Selected portions of ${ }^{1} \mathrm{H} /{ }^{1} \mathrm{H}$ NOESY spectrum of the decamer duplex acquired at $25^{\circ} \mathrm{C}$ in 20 $\mathrm{mM}$ sodium phosphate buffer in $\mathrm{D}_{2} \mathrm{O}, \mathrm{pH}$ 7.0. (A) NOEs between the downfield aromatic protons and the $\mathrm{H}^{\prime}$ ' of the sugar or the $\mathrm{H} 5$ of the pyrimidine bases indicating stacking of nucleotides; (B) NOEs between the adenosine $\mathrm{H} 2$ proton to aromatic or $\mathrm{H}^{\prime}$ protons on the opposite strand, indicating an intact helix. 

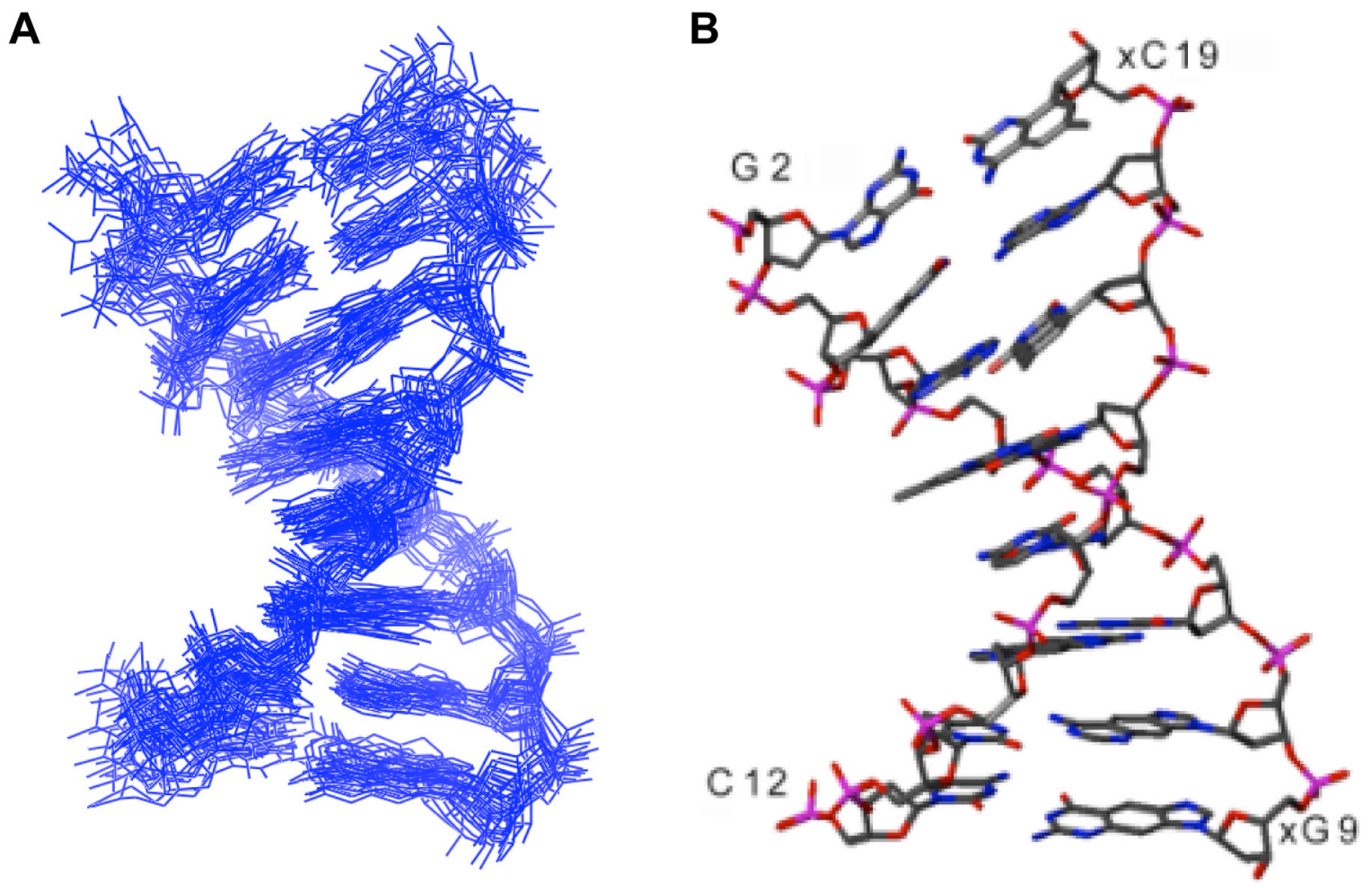

Figure 4.

Structures of the xDNA helix containing eight different bases. (A) Superposition of twenty final structures after restrained molecular dynamics and energy minimization; (B) average structure of the xDNA duplex. 


\section{A}
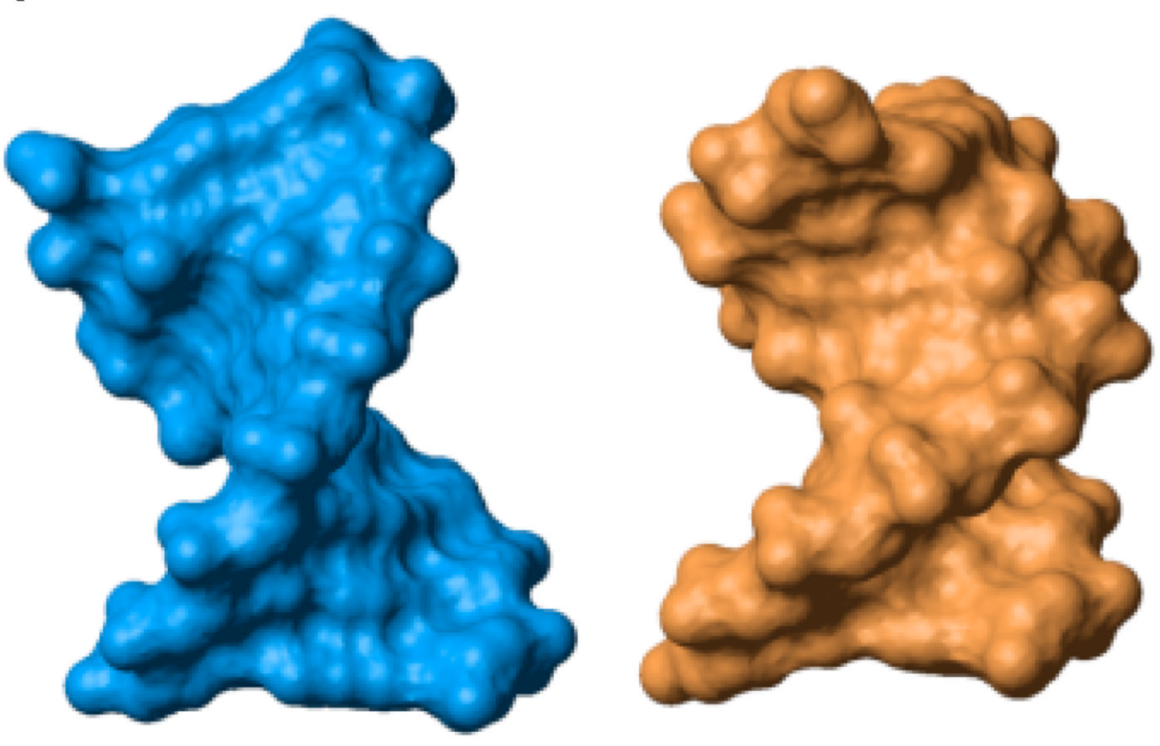

B
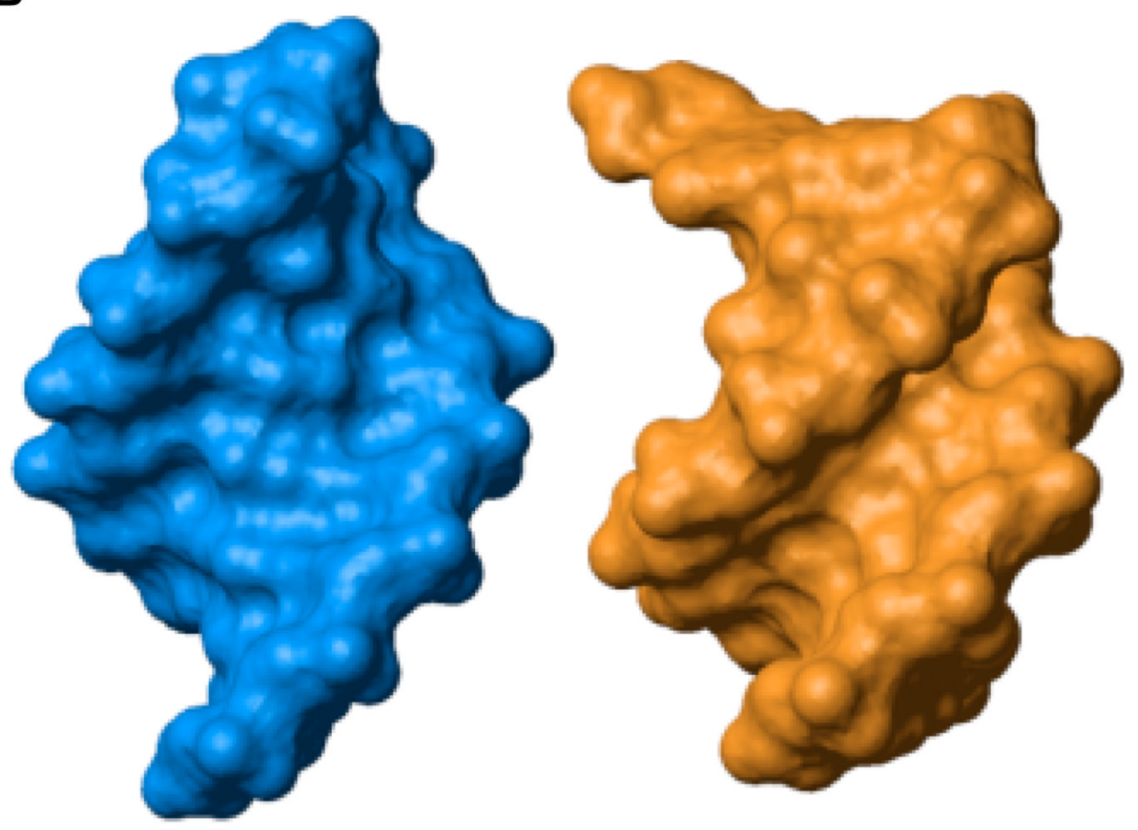

Figure 5.

Space-filling surface models showing helix shape and grooves of xDNA (cyan, on left) compared with B-DNA (orange, right). (A) View of backbone with major groove at top; (B) Minor groove view showing exceptionally wide and shallow minor groove of xDNA. 
A

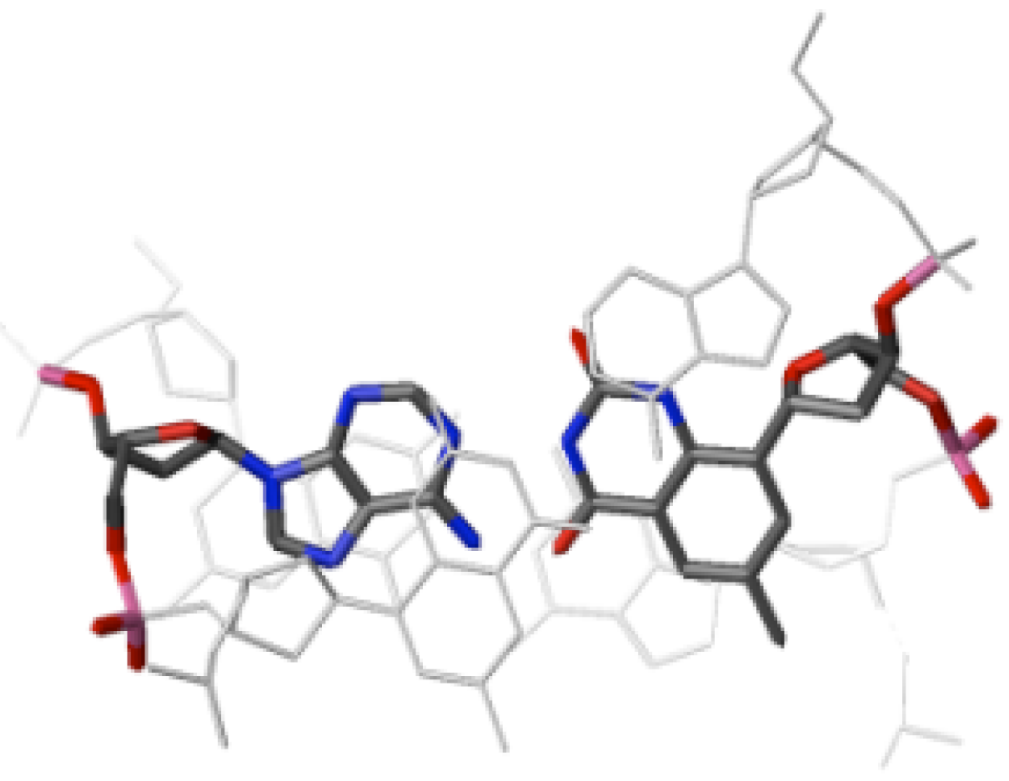

B

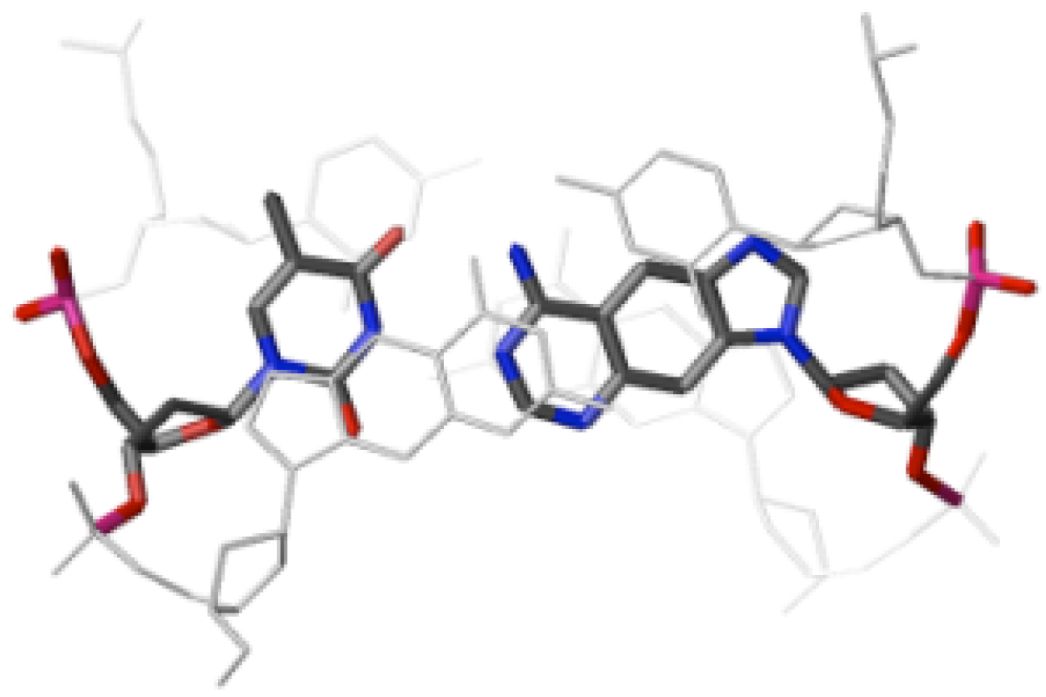

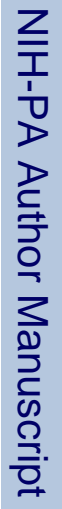



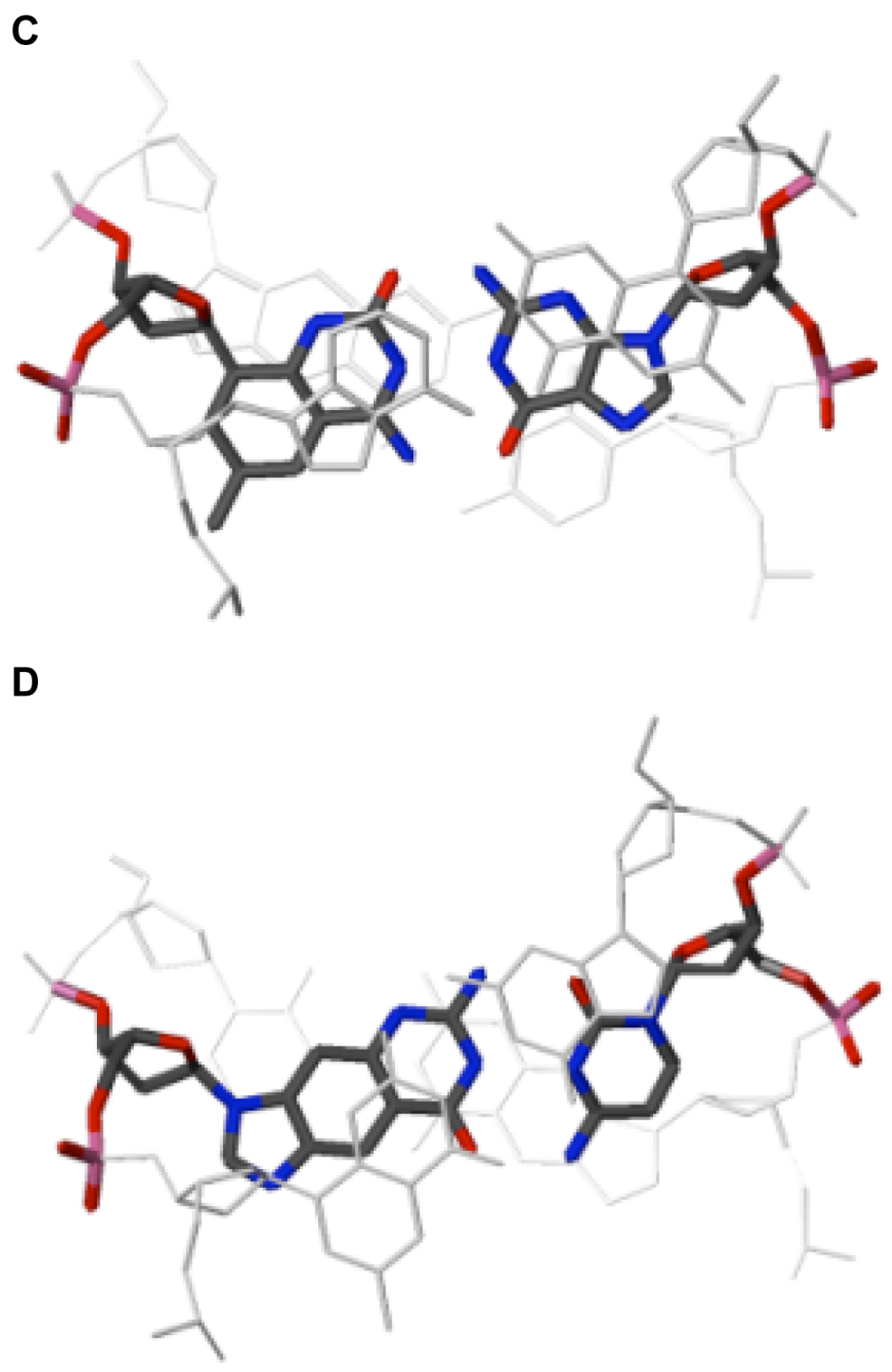

Figure 6.

Structures of four different base pairs in the xDNA helix, with the adjacent nucleotides (gray) to illustrate base stacking arrangements: (A) A4-xT17; (B) T13-xA8; (C) xC5-G16; (D) xG6C15. 


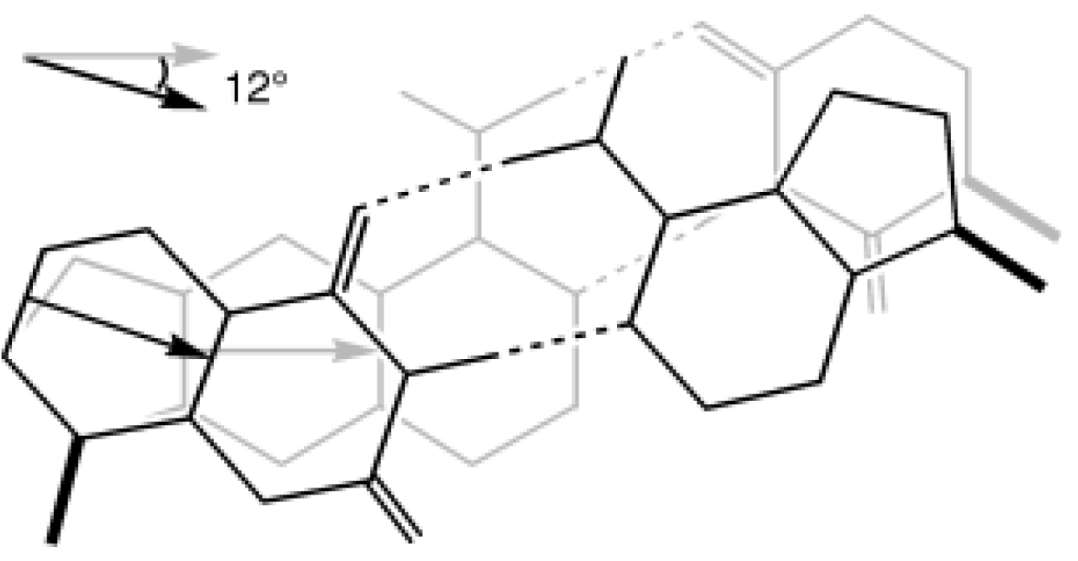

Figure 7.

Schematic overlay of xT-A (black) and xA-T (gray) base pairs drawn with conserved hydrogen bond lengths and angles, showing small geometric differences between benzo-expansion of pyrimidines and purines in xDNA pairs. Vectors of expansion are depicted with arrows. Since $\mathrm{Cl}^{\prime}-\mathrm{C} 1^{\prime}$ distances are constrained by the xDNA backbone, adjustments in hydrogen bond lengths and orientations are likely needed to compensate for the vector differences when such pairs are adjacent. 
Table 1

Structure Statistics and Atomic Rms Deviations.

\begin{tabular}{lr}
\hline Distance constraints & 635 \\
Total & 356 \\
Intranucleotide & 279 \\
Internucleotide & 29 \\
Interstrand & 80 \\
Dihedral constraints & 25 \\
Hydrogen bonds (WC base-pairs) & $11.3 \pm 3.7$ \\
Final forcing energies for distance & $<1$ \\
and dihedral constraints $(\mathrm{kcal} / \mathrm{mol})$ & \\
Average NOE Violations $(>0.2 \AA)$ & 0.25 \\
Maximum NOE Violation $(\AA)$ & 6 \\
Average Dihedral Violations $\left(>2{ }^{\circ}\right)$ & 10 \\
Maximum Dihedral Violation $\left({ }^{\circ}\right)$ & 0.01 \\
R.m.s.d. from distance constraints $(\AA)$ & 0.67 \\
R.m.s.d. from dihedral constraints $\left({ }^{\circ}\right)$ & 0.0050 \\
Deviations from idealized geometry & 0.94 \\
Bonds $(\AA)$ & 0.18 \\
Angles $\left({ }^{\circ}\right)$ & \\
Impropers $\left({ }^{\circ}\right)$ & $1.18 \pm 0.11$ \\
Heavy atom r.m.s.d. & $0.80 \pm 0.11$ \\
All $(2-10,11-19)$ & \\
Core Residues $(3-8,13-18)$ &
\end{tabular}


Table 2

Average Structural Parameters for xDNA and B-DNA

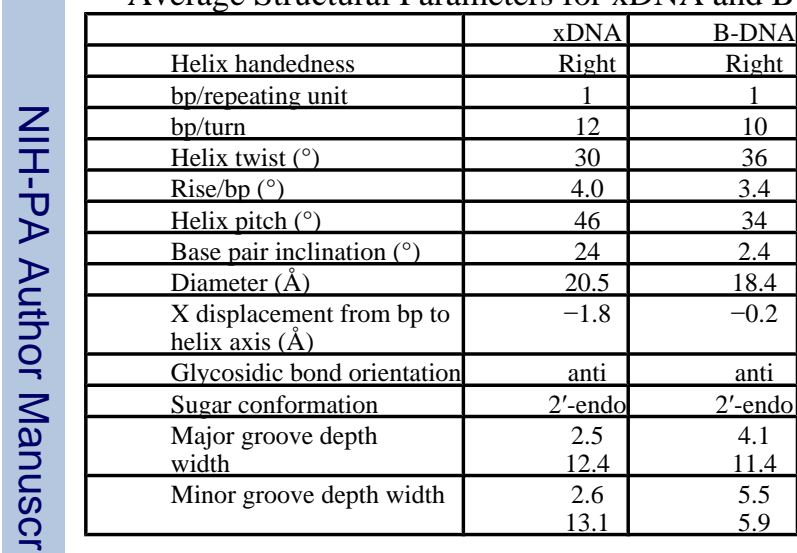

